I Universidade Federal do Rio de Janeiro (UFRJ), Programa de

Pós-Graduação em Sociologia e Antropologia, Rio de Janeiro, RJ, Brasil

annabarbaraaraujo@gmail.com

https://orcid.org/oooo-0002-2792-9931

Anna Bárbara Araujo'

\title{
CAPITALISMO DE MARCA, TRABALHO AFETIVO E PRECARIEDADE
}

Wasser. Nicolas. (2017). The promise of diversity: how

Brazilian brand capitalism affects precarious identities and

work. Bielefeld: Transcript.

Que relação pode ser estabelecida entre os seguintes perfis de jovens: vendedores cheios de estilo e atitude de uma marca de acessórios, adolescentes frequentadores dos rolezinhos em shopping centers e MCs do funk ostentação? Nicolas Wasser diria que todos estão, à sua maneira, buscando a visibilidade e o reconhecimento de suas identidades - e de sua própria existência - em um cenário marcado, por um lado, pela desigualdade no acesso aos bens sociais que os conduz para posições minoritárias e, por outro, pela sedução crescente exercida pelo capitalismo de marca [brand] sobre suas subjetividades, aspirações e afetos.

O livro de Nicolas Wasser é fruto de sua tese de doutorado defendida em 2016 pelo Programa de Pós-Graduação em Sociologia e Antropologia da Universidade Federal do Rio de Janeiro
(PPGSA-UFRJ) sob orientação da professora Bila Sorj e coorientação da professora Andrea Maihofer, da Universität Basel, na Suíça, e tem como pano de fundo o estudo de caso de uma famosa marca de óculos brasileira. $\mathrm{O}$ autor investiga a história da marca, suas estratégias de marketing e especialmente as narrativas dos funcionários das lojas e quiosques espalhados pela cidade do Rio de Janeiro além de suas interações em redes sociais - no que diz respeito ao próprio trabalho e projetos profissionais, suas identidade e opinião sobre a marca. Mais do que um estudo de caso, no entanto, Nicolas Wasser apresenta um fenômeno mais amplo e de dimensões transnacionais, que seria próprio a uma específica constelação histórica contemporânea do capitalismo e das identidades, e o faz recorrendo a di- 
versos exemplos empíricos como os já citados.

A obra lança mão, minuciosa e criticamente, de uma série de contribuições teóricas de campos distintos do conhecimento, especialmente os estudos feministas e queer, o pós-colonialismo, os estudos culturais, o (pós-)marxismo em suas diferentes vertentes e os estudos sobre trabalho e organizações, costurando criativamente relações entre esses campos que lhe permitem analisar seu objeto de maneira multissituada. $\mathrm{O}$ livro é dividido em seis capítulos, incluindo a introdução e a conclusão.

$\mathrm{Na}$ introdução, o autor apresenta sua questão primária de pesquisa, que o guiou nos primeiros estágios de produção da tese, qual seja, como o capitalismo do século XXI interage com promessas de liberação sexual (p. I3). Ou, como a aceitação e a normalização de identidades LGBT e de outras minorias, que parecem se expandir em termos econômicos (especialmente no que se refere ao trabalho e ao consumo), se traduzem (ou não) em outras esferas culturais (especialmente a do direito e da vida cotidiana). Para responder a tal questão é preciso considerar as relações entre a lógica de mercado e a vida íntima, tema bastante presente nas análises feministas e de uma certa sociologia econômica (cf. Hochschild, I983, 20I3; Zelizer, 20I I). O diferencial do texto em questão é que o autor estabelece um recorte preciso, inovador e bastante atual: a relação entre o capitalismo de marca e a lógica neoliberal de (auto)governo.

Convém explorar mais detalhadamente a diferença entre a proposta de
Nicolas Wasser e as abordagens já clássicas das autoras mencionadas: Arlie Hochschild propôs em I983 o conceito de trabalho emocional, baseado em uma pesquisa sobre o trabalho de aeromoças. A socióloga mostra que o trabalho dessas profissionais envolve a expressão de determinados estados emocionais (como alegria, sensualidade, empolgação) que eram aprendidos em cursos de treinamento oferecidos pela empresa. A necessidade de sentir e transmitir emoções se torna uma demanda do trabalho, o que gera conflitos para as aeromoças no que diz respeito a manejar sua apresentação de si profissional e sua personalidade fora do trabalho. Algumas aeromoças relatam dificuldade em se desvencilhar do estado efusivo e alerta próprio de sua atuação no avião depois de um longo dia de trabalho, por exemplo.

Já o argumento de Viviana Zelizer vai na direção de mostrar que as trocas econômicas criam, recriam e negociam laços sociais e, em especial, laços íntimos. Um caso exemplar, nesse sentido, é o das indenizações. Já é possível no Brasil, por exemplo, pedir indenização em caso do chamado "abandono afetivo" por um dos pais. As indenizações têm o potencial de transferir para a linguagem monetária prejuízos de outra natureza; nesse caso específico, trata-se de ressarcir economicamente a ausência de laços emocionais. Assim, a economia não é para Zelizer uma dimensão separada da vida (com regras e funcionamento específicos) e deve ser estudada como parte constitutiva das relações sociais entre pessoas. 
Para Wasser, a lógica neoliberal de (auto)governo é de tal ordem, que a diferenciação entre o "eu profissional" e o "eu pessoal" tal como defendida por Hochschild, já não tem mais lugar. Ao contrário, o autor vai mostrar, com relação ao seu estudo de caso, que as demandas da empresa tendem a ser abraçadas e celebradas entusiasticamente pelos funcionários e, mais do que isso, percebidas em termos de crescimento pessoal. Ou seja, em última instância, os estados emocionais produzidos pelos funcionários em seu ambiente de trabalho não são vistos como falsos ou conflitantes, como ocorria com as aeromoças entrevistadas por Hochschild, mas como a verdadeira expressão de sua personalidade e como produtores de uma versão aprimorada de si mesmos.

Trata-se, portanto, de um cenário em que os empreendimentos capitalistas conseguem solicitar e se apropriar dos afetos e emoções de modo muito mais contundente do que aquele citado por Hochschild, uma vez que atuam fortemente sobre os desejos dos trabalhadores. Esse cenário é denominado pelo autor capitalismo de marca. As marcas seriam hoje as ferramentas governamentais por meio das quais as lógicas do mercado capitalista se entrelaçam e até mesmo se fundem com as vidas, aspirações e gostos das pes soas (p. I4). É justamente a especificidade desse cenário que a abordagem de Zelizer falha em captar. Sua ênfase na relação entre mercado (capitalista) e intimidade acaba por obscurecer as especificidades históricas dessa relação no capitalismo tardio, e assim não esmiúça o funcionamento da economia nos dias atuais, cuja relação com a vida cotidiana se alterou profundamente ao longo dos anos.

No segundo capítulo, o autor discute como a sexualidade e a celebração da diversidade e da diferença (principalmente sexual e racial) são centrais para o capitalismo contemporâneo em geral e em particular para a marca analisada. Além disso, Wasser mostra que as marcas produzem condutas específicas por meio do governo dos desejos e identidades dos trabalhadores e consumidores. Em resumo, as marcas prometem mais do que produtos, mas experiências, estilos de vida e sentimentos aos consumidores. Ao mesmo tempo, instauram regimes de conduta, com base especialmente no corpo e na sexualidade das pessoas. No caso da marca estudada, as estratégias publicitárias apelam para a emulação da sexualidade, ao mesmo tempo em que a aparência "alternativa" dos trabalhadores encena a promessa de um estilo de vida autêntico e legítimo. Esse fenômeno ultrapassa os limites da publicidade, posto que a afetividade e a identificação dos trabalhadores - em sua maioria, jovens de grupos minoritários (gays, lésbicas e negros das periferias urbanas) - com a marca, garantida por uma série de estratégias de marketing, é fundamental, uma vez que tem a capacidade de gerar o comprometimento - e até devoção - dos trabalhadores e aumenta o potencial de lucro da empresa.

O terceiro capítulo aborda os processos de identificação que os vendedores estabelecem com a marca tendo 
como foco não seu discurso e suas estratégias, como no capítulo anterior, mas as narrativas dos vendedores. Essas narrativas revelam processos e projetos individuais de criação, valorização e estilização da diferença. Retomando o argumento de Stuart Hall (I996), o autor entende as identidades como pontos de sutura entre o que pode ser entendido como as duas dimensões dos processos de assujeitamento, quais sejam, a sujeição a determinados posicionamentos sociais e a produção de subjetividade e de sujeitos. Segundo Wasser, para que o (auto)governo proposto pela marca seja bem-sucedido, ele precisa se enxertar em modos e estilos de ser específicos, ou seja, depende menos da construção de marcos regulatórios superiores e mais da captura das "almas" e selves dos empregados. Essa captura, é importante dizer, nunca é completa ou inescapável, mas parece ter efeitos bastante fortes no caso analisado. Nesse sentido, é significativo que todos os vendedores entrevistados pelo autor se identifiquem fortemente com a empresa e, mais do que isso, articulem - com a marca - e negociem - individual e coletivamente - identidades concretas relativas ao estilo de vida, sexualidade, raça e juventude (p. Iog).

O autor apresenta e discute, no capítulo quatro, a noção de trabalho afetivo. Tal empreendimento se dá por meio da análise crítica de noções mais ou menos estabilizadas na teoria social como trabalho emocional, trabalho sexual (noção alemã que não se confunde com o trabalho das prostitutas), trabalho corporal, cordialidade (como ordenação afetiva de hierarquias) e o próprio conceito de trabalho afetivo (à luz de autores da chamada virada afetiva e do pós-operaísmo). Interessa discutir como os vendedores em questão têm seus sentimentos, modos de ser e agir e identidades alterados pelo éthos empresarial e tornados parte de seu trabalho diário. Desse modo, o trabalho não produz apenas mercadorias, mas também sujeitos sociais (p. I72). Além disso, é por meio dos sentimentos que os vendedores se relacionam consigo e com os outros (p. I77). A combinação desses dois aspectos é denominada pelo autor trabalho afetivo.

No quinto capítulo, ao apresentar narrativas de vendedores que deixaram a empresa, o autor mostra como eles habitam posições precárias. Diferentemente de parte considerável da sociologia do trabalho, no entanto, Nicolas Wasser compreende a precariedade não apenas como sinônimo de inseguranças no trabalho (como baixos salários ou ausência de contratos, por exemplo), também relevantes para seu estudo. Inspirado por teóricos do reconhecimento e pelos estudos queer (cf. Butler, 2004) o autor entende a precariedade como algo também presente no nível das subjetividades, e que diz respeito ao reconhecimento social instável e incerto, no caso da marca, dependente do sabor dos mercados e da capacidade de performar a própria diversidade em termos lucrativos, o que pode resultar em investimentos pessoais frustrados no âmbito do trabalho, além da adesão individual a lógicas neoliberais que invisibiliza as desigualdades estruturais. 
Nicolas Wasser levanta a questão de como compreender a precariedade, um termo tão polissêmico e que já há algum tempo habita a linguagem dos movimentos sociais, sindicatos e partidos políticos de esquerda. Nesses contextos, o termo ora expressa a conjuntura do trabalho, ora tipifica um modo de vida, caracterizado pela sua condição de anormalidade. Vale lembrar que em alguma medida essa dualidade já estava prevista quando da origem do conceito, cunhado na sociologia por Robert Castel (I998), que utilizava a noção de precariedade para denotar uma dupla posição desfavorável (ou anômica) ocupada pelas massas: na divisão do trabalho e na vida social. É esta última esfera - embora atualizada e revista - que chama atenção das teóricas feministas da precariedade, pois ela permite que se entenda a precariedade como um governo que instaura insegurança, medo e vulnerabilidade e que não se resume ao mundo do trabalho, mas que, ao contrário, passa a ser um motor para a vida. Judith Butler (2009: xiii) afirma que a "a vida precária caracteriza aquelas vidas que não se qualificam como reconhecíveis, legíveis ou passíveis de luto". Nesse sentido é um conceito que pode amalgamar mulheres, pessoas LGBT, pobres e pessoas sem Estado (Id). As vidas precárias, são as mais vulneráveis, estão mais expostas à violência, à escassez de alimento e habitação, ao sofrimento e à morte.

No caso dos trabalhadores estudados pelo autor, as lógicas da insegurança e da incerteza próprias da precariedade se apresentam nas metas de venda e nos ritmos de trabalho, mas também, e talvez principalmente, no fato de que o reconhecimento é caudatário da capacidade de - e dos esforços para - performar continuamente a si mesmo de modo positivo e valorizável por parte daqueles que não têm sua identidade aceita de início, ou seja, os vendedores marcados pela "diferença" sexual e racial. O argumento de Wasser é de que o cenário neoliberal empurra cada vez mais pessoas para posições precárias uma vez que exige esforços hercúleos e infindáveis de autoaprimoramento em troca da promessa, muitas vezes não cumprida, de reconhecimento e aceitação de suas identidades que são, desde o início, colocadas em suspeita.

A conclusão dedica-se a retomar resumidamente os principais argumentos e conceitos desenvolvidos ao longo do livro de modo a reforçar a tese de que a pluralização das identidades valorizadas no trabalho - e, poder-se-ia dizer, pelo capitalismo - não se converte, efetivamente, em mais direitos para as minorias ou mais justiça social. Além disso, a noção de diversidade acaba por denotar - e encerrar - grupos específicos (e não hegemônicos), de modo que a diversidade - assim como a sexualidade e a raça seja sempre a diversidade dos outros (p. 275).

Dessa forma, a publicação de Nicolas Wasser oferece uma contribuição relevante e original ao campo dos estudos sobre capitalismo e diversidade. Além disso, ao comparar tendências do mercado de trabalho globais e o contexto nacional do trabalho em ser- 
viço, o autor avança na discussão desse setor que, a despeito de sua grande importância econômica, ainda figura de modo marginal nos estudos sobre trabalho e organizações nacionais, especialmente no que se refere aos diálogos estabelecidos entre o trabalho e o afeto, a sexualidade e o corpo.

Recebida I7/2/20I7 | Revista 5/4/20I7 | Aprovada 3/5/20I7

\section{REFERÊNCIAS BIBLIOGRÁFICAS}

Butler, Judith. (2009). Performativity, precarity and sexual politics. Revista de Antropología Iberoamericana, 4/3, p. i-xiii.

Butler, Judith. (2004). Precarious life: the powers of mourning and violence. London: Verso.

Castel, Robert. (I998). As metamorfoses da questão social: uma crônica do salário. Tradução de Iraci D. Poleti. Petrópolis: Vozes.

Hall, Stuart. (I996). Introduction: Who Needs 'Identity'?. In: Hall, Stuart \& Du Gay, Paul (orgs.). Questions of cultural identity. London/New Delhi: Thousand Oaks/Sage, p. I-I7.

Hochschild, Arlie. (20I3). Éthique du care et capitalisme émotionnel. In: Paperman, Patricia \& Molinier, Pascale (eds.). Contre l'indifférence des privilégiés: À quoi sert le care. Paris: Payot. Hochschild, Arlie. (1983). The managed heart: commercialization of human feeling. Berkeley: University of California Press.

Zelizer, Viviana. (20II). A negociação da intimidade. Petrópolis: Vozes.

Anna Bárbara Araujo é doutoranda e mestre pelo Programa de Pós-Graduação em Sociologia e Antropologia da Universidade Federal do Rio de Janeiro (PPGSA-UFRJ). Suas pesquisas situam-se nas áreas de trabalho e gênero, e mais especificamente no tema do cuidado. Possui artigos publicados sobre a dimensão moral e emocional do trabalho de cuidado. 